\title{
Carbenaporphyrins: A Missing Ligand in N-Heterocyclic Carbene Chemistry
}

\author{
Theo Maulbetsch, and Doris Kunz*
}

Institut für Anorganische Chemie, Eberhard Karls Universität Tübingen, Auf der Morgenstelle 18, D-72076 Tübingen

E-mail: Doris.Kunz@uni-tuebingen.de

Supporting information for this article is given via a link at the end of the document.

\begin{abstract}
The synthesis of an NHC-containing porphyrin ligand is presented. The formally antiaromatic $20 \pi \mathrm{e}^{-}$macrocyclic framework can be obtained via a 1,3-dipolar cycloaddition ("click-reaction") to form two triazole moieties which were alkylated to the respective triazolium macrocycle. Optical properties combined with TD-DFT studies verify an aromatic character for each heterocyclic moiety rather than an antiaromatic macrocycle. Deprotonation with lithium bases and transmetallation to scandium was successful. While the geometric features of the carbenaporphyrin ligand strongly resemble those of porphyrin, DFT calculations reveal a stronger electron donating ability of the new ligand.
\end{abstract}

Porphyrins are an abundant ligand class in nature as well as within coordination chemistry. ${ }^{[1]}$ Complexes of almost every metal ion are known with these ligands, whose diverse properties also defines the reactivity and application, e.g. catalysis, ${ }^{[2]}$ supramolecular chemistry, ${ }^{[3]}$ chemosensors, ${ }^{[4]}$ and organic electronics. ${ }^{[5]}$ The aromatic $18 \pi \mathrm{e}^{-}$macrocyclic structure has been adapted by nature as well as by chemists varying the substituents at the porphyrin ring, ${ }^{[6]}$ synthesizing expanded and contracted variations ${ }^{[7,8]}$ as well as altering the nature of the donor atoms or the position of the heteroatoms. ${ }^{[8]}$ An interesting example of the latter are so-called $\mathrm{N}$-confused porphyrins, ${ }^{[9]}$ in which one or two $\mathrm{C}$ atoms instead of the $\mathrm{N}$ atoms of the pyrrole moieties are coordinated to the metal. Thus, the carbon donor atom gains carbene character ${ }^{[10]}$.

$\mathrm{N}$-heterocyclic carbene ligands (NHC) are stable ("bottleable") singlet carbenes that show strong overall donor-properties which can be beneficial in coordination chemistry. ${ }^{[11]}$ They are suitable to build up $\pi$-conjugated poly(NHC) ligands ${ }^{[12]}$ and porphyrin-fused $\mathrm{NHCs} .{ }^{[13]}$ A porphyrin with an embedded NHC moiety is also known. ${ }^{[14]}$ The idea to not only invert pyrrole moieties of the porphyrin, but to substitute them by $\mathrm{NHCs}$ existed since long ${ }^{[15]}$ - however, its realization has remained elusive. Our own early research on this topic showed that precursors based on methylene-connected pyrrole and imidazolium units are not suitable for this purpose due to elimination reaction upon deprotonation ${ }^{[16,17]}$ and therefore, we introduced a carbazole moiety, ${ }^{[18]}$ in which connecting $\mathrm{sp}^{2}$ carbon atoms prevent such an elimination reaction. ${ }^{[16]}$ This still led to major synthetic problems in constructing an alternating imidazolium-pyrrole macrocycle. ${ }^{[19]}$ However, triazole instead of imidazole based NHCs are readily accessible by a 1,3-dipolar cycloaddition ${ }^{[20-22]}$ and thus could be used to build up the desired macrocycle 1 based on carbazole $\mathbf{2}$ using compounds 3 and $\mathbf{4}$ as building blocks (Scheme 1). After initial attempts ${ }^{[23]}$ we set out again to synthesize the formally antiaromatic $\left(20 \pi \mathrm{e}^{-}\right)$carbazole-triazolylidene porphyrin (CTP) 1 , whose successful synthesis and their special properties are the objectives of this work.

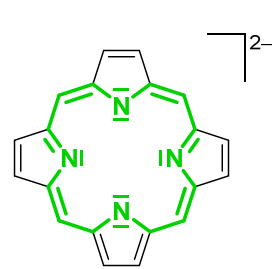

porphyrin ligand

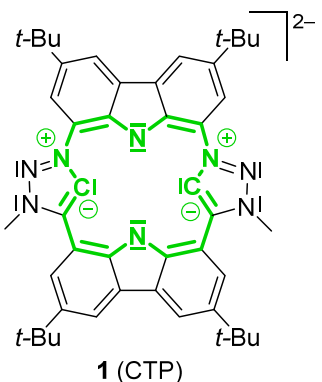

$1(\mathrm{CTP})$

Figure 1. The regular porphyrin ligand (left) and our carbazole-triazolylidene porphyrin (CTP) 1 . The conjugated $\pi$-system (green) is Hückel-aromatic in porphyrin $\left(18 \mathrm{e}^{-}\right)$, and could be flexible in $1\left(18-20 \mathrm{e}^{-}\right)$depending on the significance of certain resonance structures in the mesoionic carbene moieties.

The key step of the synthesis is the copper catalyzed alkyne-azide cycloaddition (CuAAC), ${ }^{[24]}$ the so-called click-reaction, ${ }^{[25]}$ in which both triazole moieties are build up under formation of the macrocycle. Both alkyne $\mathbf{3}$ and azide $\mathbf{4}$ are literature known compounds and can be obtained from carbazole 2. ${ }^{[26,27]}$ The azide formation from the respective 1,8-bromocarbazole did not work in our hands following the literature procedure. ${ }^{[27]}$ Instead, we applied a Sandmeyer type reaction ${ }^{[28]}$ and succeeded in isolating 4 in a $93 \%$ yield from the respective 1,8-diaminocarbazole as a thermally stable (slow decomposition above $100^{\circ} \mathrm{C}$ ) but light sensitive product. The tert-butyl groups in $\mathbf{2}$ are not only beneficial as protecting groups, but they also enhance the solubility of the product.

The copper catalyzed 1,3-dipolar cycloaddition to form the triazole macrocycle $\mathbf{5}$ was described by Arnold to proceed only with $17 \%$ yield using a high catalyst loading and TBTA (tris((1-benzyl-1H-1,2,3-triazol-4-yl)methyl)amine) as ligand. ${ }^{[29]}$. After optimizing the conditions of this reaction as regards concentration, solvent, and stoichiometry of the reactants, we were able to isolate macrocycle $\mathbf{5}$ in $52 \%$ yield as a colorless crystalline product. 


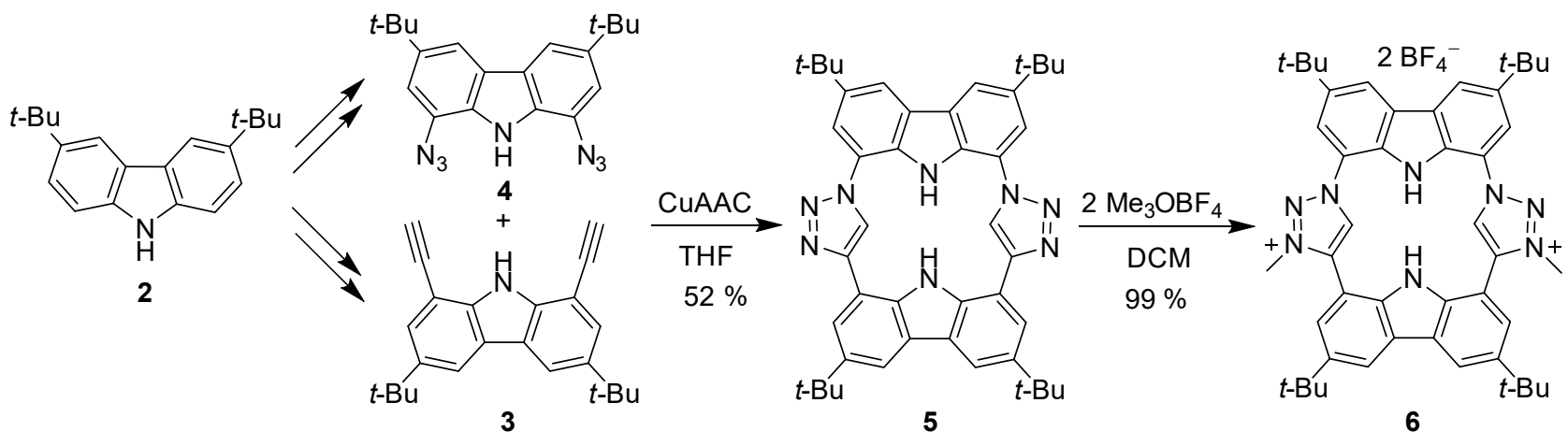

Scheme 1. Synthesis of macrocycle $\mathbf{5}$ in a CuAAC reaction of $\mathbf{3}$ and $\mathbf{4}$, which both are derived from carbazole $\mathbf{2}$, and methylation to the CTP precursor $\mathbf{6}$.

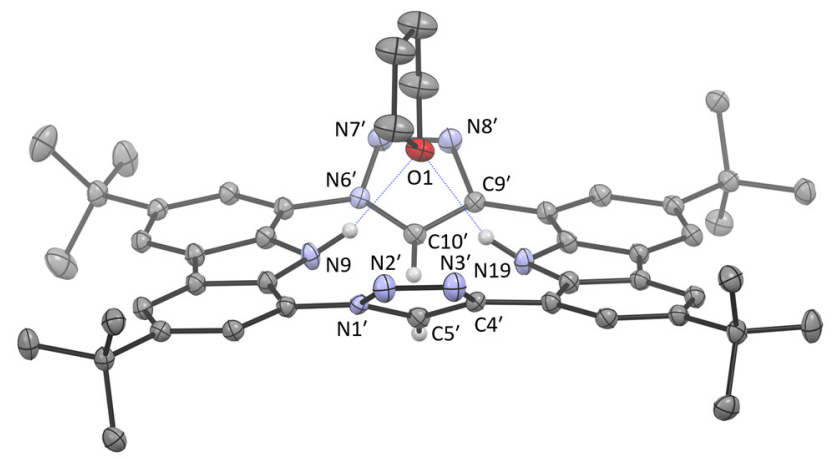

Figure 2. The solid-state molecular structure of macrocycle $\mathbf{5}$ (anisotropic atomic displacement parameters at $50 \%$ probability level). Hydrogen atoms (except for the $\mathrm{N}-\mathrm{H}$ and triazole $\mathrm{C}-\mathrm{H})$ and three co-crystallized THF molecules are omitted for clarity. One THF is coordinated via $\mathrm{H}$-bridges $(\mathrm{O} 1-\mathrm{H} 9=2.095 \AA, \mathrm{O} 1-\mathrm{H} 19=2.171$ A).

The ${ }^{1} \mathrm{H}$ NMR spectrum (THF- $\mathrm{d}_{8}$ ) shows 5 aromatic signals of equal ratio (four from the chemically inequivalent carbazoles at $8.10,8.18$, 8.24 and $8.41 \mathrm{ppm}$, and one from the two equivalent triazole moieties at $9.82 \mathrm{ppm})$, two broad NH signals (10.19 (Carb-N) and 9.43 ppm (Carb-C)) and two singlets for the tert-butyl groups (1.54 and $1.56 \mathrm{ppm}$ ). X-ray structure analysis of a colorless single crystal obtained from slow evaporation of a solution in tetrahydrofuran - confirms the identity of 5 (Figure 2). The absence of color already indicates that an aromatic $18 \mathrm{e}^{-}$annulene core, like in porphyrin, cannot be expected. Indeed, the individual aromaticity of the carbazole and triazole moieties is retained which results, in addition to steric congestion of the $\mathrm{C}-\mathrm{H}$ and $\mathrm{N}-\mathrm{H}$ protons, in a small inclination of the carbazole planes $\left(9.2^{\circ}\right)$ and a larger of the triazole planes $\left(72.3^{\circ}\right)$ into the opposite direction (tilting of the triazole plane against the carbazole plane $36^{\circ}$ (mean)), so that the $\mathrm{C}-\mathrm{H}$ and $\mathrm{N}-\mathrm{H}$ groups are pointing away from each other. It is enhanced by $\mathrm{N}-\mathrm{H}$ bridges to one molecule of tetrahydrofuran. This coordination provides an explanation for the broadened $\mathrm{NH}$ signals in the ${ }^{1} \mathrm{H}$ NMR spectrum.

The alkylation of $\mathbf{5}$ to form the triazolium moieties in $\mathbf{6}$ did not proceed with methyl iodide but required the stronger Meerwein's salt (trimethoxy tetrafluoroborate). The dicationic macrocycle $\mathbf{6}$ was obtained quantitatively as a colorless crystalline material. In the ${ }^{1} \mathrm{H}$ NMR spectrum product 6 is identified by the signal of the methyl groups at $4.55 \mathrm{ppm}$. Although the NH groups are chemically inequivalent, only one (broad) signal $(2 \mathrm{H})$ at $9.40 \mathrm{ppm}$ is observed, possibly due to fast exchange. Very characteristic is the downfield shifted signal of the triazolium $\mathrm{C}-\mathrm{H}$ moiety at $9.92 \mathrm{ppm}$ which indicates a higher acidic character of the hydrogen atom than in $\mathbf{5}$ and its carbon chemical shift at $\delta\left({ }^{13} \mathrm{C}\right) 132.2 \mathrm{ppm}$ compared to $124.8 \mathrm{ppm}$ in $\mathbf{5}$.

The X-ray structure analysis of single crystals obtained from slow evaporation of a solution in tetrahydrofuran confirms the successful formation of the triazolium macrocycle 6 .

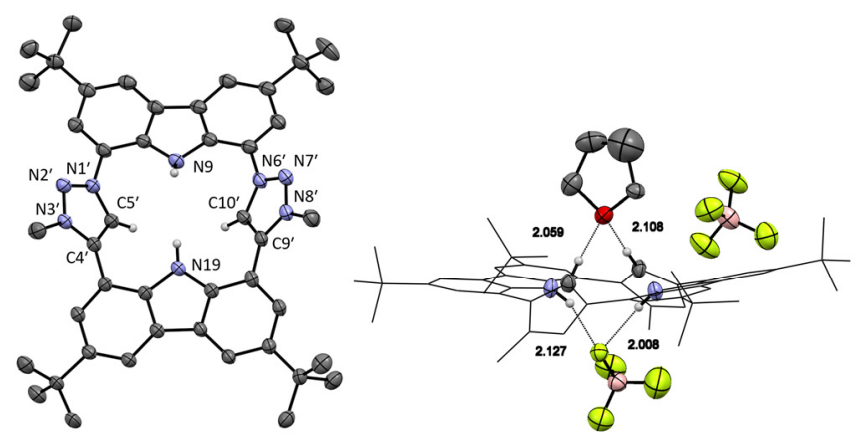

Figure 3. Two views of the solid-state molecular structure of the triazolium macrocycle 6 (anisotropic atomic displacement parameters at $50 \%$ probability level) Left: Hydrogen atoms (except for the acidic $\mathrm{N}-\mathrm{H}$ and triazolium $\mathrm{C}-\mathrm{H}$ ), the two $\mathrm{BF}_{4}^{-}$counterions and one coordinated THF molecule are omitted for clarity. Right: Hydrogen bonding between one $\mathrm{BF}_{4}^{-}$counterion to the carbazole $\mathrm{N}-\mathrm{H}$ and between one THF and the triazolium hydrogen atoms. The macrocycle is depicted in wireframe for clarity reasons. 
Similar to macrocycle $\mathbf{5}$, hydrogen bonding to acidic hydrogen atoms is observed, which in the case of $\mathbf{6}$ also includes the triazolium hydrogen atoms. They have short contacts to the tetrahydrofuran oxygen, while the carbazole $\mathrm{N}-\mathrm{H}$ atoms are coordinated to the fluorine atom of one of the $\mathrm{BF}_{4}^{-}$counterions. As already recognized in $\mathbf{5}$, the carbazole planes are only slightly tilted toward each other, while the hydrogen bonding to the fluorine atom is realized through a small tetrahedralization of the nitrogen atoms (sum of angles at N9 and $\mathrm{N} 19=350^{\circ}$ ). The triazolium planes are inclined by $87.1^{\circ}$ and are tilted by an average of $44.1^{\circ}$ against the carbazole planes (mean values).

Like macrocycle 5 the CTP precursor 6 is a colorless compound, (porphin is dark red), which already indicates that 6 lacks antiaromatic character $\left(20 \mathrm{e}^{-}\right.$; e.g. isophlorin $\left.{ }^{[30]}\right)$ nor is it a macrocyclic aromatic $\pi$-system like porphyrin $\left(18 \mathrm{e}^{-}\right)$. Instead, it resembles other carbazole porphyrinoids. ${ }^{[31]}$ In the UV/VIS spectrum (THF) an absorption maximum at $359 \mathrm{~nm}$ is detected, while it lacks the characteristic Soret band at $400-450 \mathrm{~nm}$ of porphyrines that originates from a $\pi-\pi^{*}$ transition of the delocalized $18 \mathrm{e}^{-}$aromatic ring system. ${ }^{[32]}$ DFT calculations confirm that the carbazole and NHC moieties keep their separate aromatic character and only very small contributions to the molecular orbitals of the other moieties is observed, e.g. the HOMO is almost fully localized on one carbazole moiety (Figure 4). TD-DFT calculations indicate that the first relevant absorption maximum at $359 \mathrm{~nm}$ consists of electronic transitions from a carbazole centered orbital (HOMO-3) to an unoccupied orbital of the triazole moieties (LUMO+1).

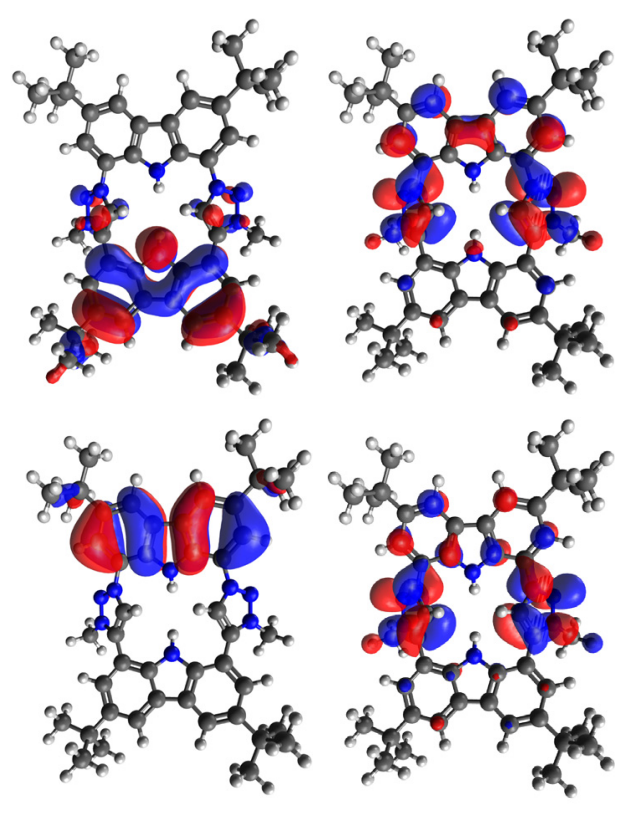

Figure 4. HOMO (top left) and LUMO (top right) of 6 and the orbitals HOMO-3 (bottom left) and LUMO+1 (bottom right) whose transition (374 nm) contributes strongest to the absorption at $359 \mathrm{~nm}$ (isosurface 0.02).

Therefore, it is comprehensible that 6 exhibits fluorescence. Excitation at $388 \mathrm{~nm}$ in THF leads to a broad emission band with a maximum at $565 \mathrm{~nm}$. In solid state the excitation band is broader, and the maximum shifted to $380 \mathrm{~nm}$. Irradiation at $380 \mathrm{~nm}$ leads to a hypsochromic shift of the emission maximum to $492 \mathrm{~nm}$.
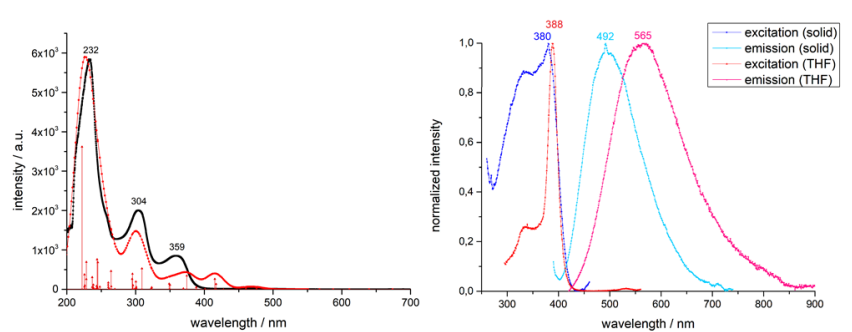

Figure 5. Left: experimental (black) and calculated (red) absorption spectrum of 6 (TD-DFT B3LYP DEF2-TZVP, CPCM(THF)). Right: excitation and emission spectra of 6 in solid state (excitation at $380 \mathrm{~nm}$ ) and in solution (excitation at $388 \mathrm{~nm}$; tetrahydrofuran, $c=10^{-3} \mathrm{M}$ ).

Deprotonation of macrocycle 6 with 4 equiv. of lithium bis(trimethylsilyl)amide led to isolation of the carbene porphyrine dilithium complex 7 as a yellow solid along with two equivalents of $\mathrm{LiBF}_{4}$, which was not removed due to its similar polarity (Scheme 2). Complex 7 was identified in the ${ }^{1} \mathrm{H}$ NMR spectrum via the absence of the $\mathrm{N}-\mathrm{H}$ and triazole $\mathrm{C}-\mathrm{H}$ peaks as well as a high-field shift of the aromatic signals of the two carbazole moieties $\left(7.69,8.03,8.22(2 \mathrm{x}) \mathrm{ppm}\right.$. In the ${ }^{13} \mathrm{C}$ NMR spectrum, the signal of the mesoionic carbene carbon atom is detected at $187.9 \mathrm{ppm}$, which is $13-18 \mathrm{ppm}$ lower than that of typical free mesoionic carbenes $(201-206 \mathrm{ppm}){ }^{[20,21]}$ This fits well with the expected incremental chemical shift upon coordination of lithium. ${ }^{[3]}$ In the ${ }^{7}$ Li NMR spectrum, a broad peak at 0.6 ppm indicates a fast ion exchange between complex 7 and $\mathrm{LiBF}_{4}$. Cooling to $-80^{\circ} \mathrm{C}$ slows down this exchange so that separate signals for complex 
7 at typical $1.90 \mathrm{ppm}^{[34]}$ and $\mathrm{LiBF}_{4}(-0.6 \mathrm{ppm})$ can be observed. According to DFT calculations each lithium atom is coordinated in an $N, C, N-\eta^{3}$-coordination mode by the CTP ligand and by two THF molecules, resulting in a $C_{2}$ symmetric complex (see Supporting Information), while in dilithio tetraphenylporphyrin, an $\eta^{4}$-coordination of the pyrrole nitrogen atoms to both lithium ions as well as coordination of one $\mathrm{Et}_{2} \mathrm{O}$ molecule per lithium atom was revealed by X-ray structure analysis. ${ }^{[35]}$ In the ${ }^{13} \mathrm{C}$ NMR spectrum of complex 7 at $-80{ }^{\circ} \mathrm{C}$ the simple signal set of the $C_{2}$ symmetric complex is observed. The carbene signal is broadened but the ${ }^{1} J_{\text {Lic }}$ coupling is not resolved (which is typical for $\mathrm{Li}$ carbene complexes due to fast $\mathrm{Li}$ exchange).

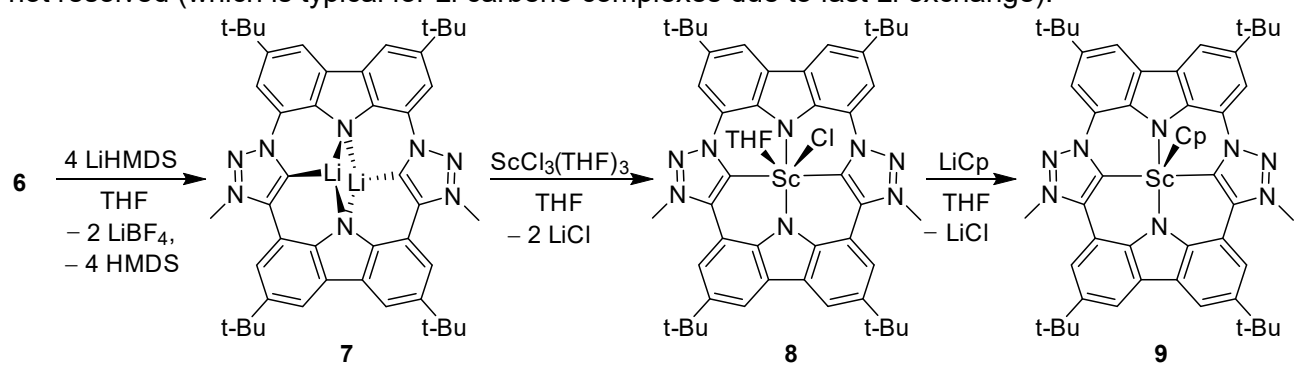

Scheme 2. Deprotonation of the macrocycle 6 to yield the dilithium complex $\mathbf{7}$ and synthesis of the CTP scandium complexes 8 and $\mathbf{9}$. Likely two THF molecules are coordinated to each of the lithium atoms in complex 7.

Transmetallation of 7 with scandium trichloride in tetrahydrofuran resulted in an orange solution of the desired scandium porphyrin complex 8 (Scheme 2). Compared to the dilithium complex 7, the signals of the aromatic protons in the ${ }^{1} \mathrm{H}$ NMR spectrum are slightly shifted to lower field, which coincides well with the increased Lewis acidity of scandium. Due to the strong quadrupole moment of the scandium nucleus $\left({ }^{45} \mathrm{Sc}: I=7 / 2\right)$, the carbene signal could not be detected. However, a ${ }^{45} \mathrm{Sc}$ NMR spectrum confirms the formation of a new scandium complex with a signal at $285.0 \mathrm{ppm}$, while the signal of the starting material $\left[\mathrm{ScCl}_{3}(\mathrm{THF})_{3}\right](217.8 \mathrm{ppm})$ is no longer observed.

From an oversaturated solution of $\mathbf{8}$ in tetrahydrofuran, orange single crystals were obtained and subjected to X-ray structure analysis. The molecular structure (Figure 5) confirms the $\eta^{4}$ coordination mode of the CTP ligand to scandium by substitution of two chlorido and two tetrahydrofuran ligands. The CTP ligand takes in a basal coordination, so that the scandium is located $0.99 \AA$ above the plane spanned by the coordinating atoms N9-C5'-N19-C10'. This coordination is typically found in porphyrin lanthanoid complexes, which leads to cis coordination of additional ligands. ${ }^{[36]}$ Only two porphyrin scandium chlorido complexes (intense purple) are structurally characterized so far. ${ }^{[37,38]}$ Both have a coordination number of 5 and the Sc is located $0.6-0.7 \AA$ above the porphyrin coordination plane. In complex 8 the additional tetrahydrofuran ligand leads to a coordination number of 6 in a distorted prismatic arrangement. The carbazole planes are almost coplanar $\left(4.0^{\circ}\right)$ and the inclination of the triazole planes is reduced to only $44.1^{\circ}$. They are tilted against the carbazole planes by $22^{\circ}$ (mean). The angles at the carbene atoms (N1'-C5'-C4' 102.8 , N6'-C10'-C9' $103.4^{\circ}$ ) are reduced (by $\left.3^{\circ}\right)$, compared to the carbene precursor 6 as it is typically found for $\mathrm{NHC}$ ligands and their respective azolium precursors.

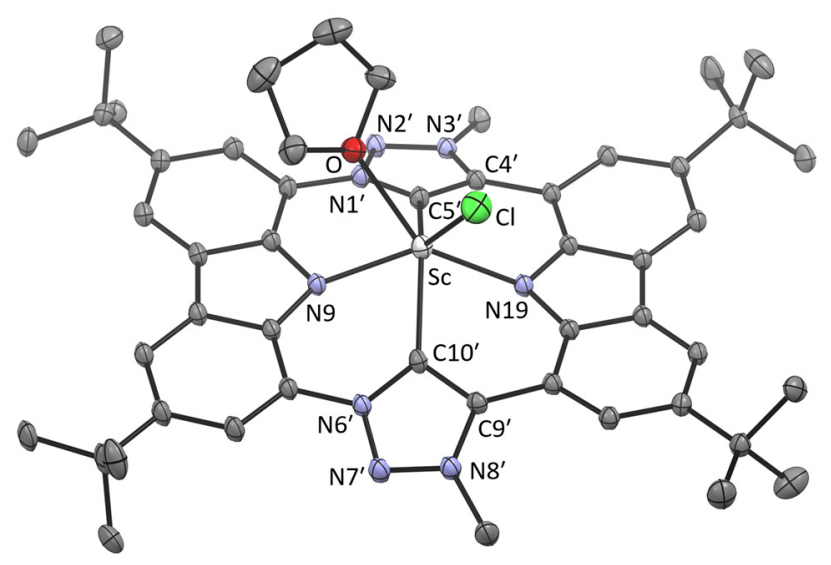

Figure 5. The solid-state molecular structure of $\mathbf{8}$. Anisotropic atomic displacement parameters shown at $50 \%$ probability and hydrogen atoms are omitted for clarity.

While the geometric features of the CTP coordination to Sc are similar to that of the porphyrin ligand, the electronic properties of the carbene moiety should impart a stronger electron donating character to the CTP ligand. Therefore, we calculated the Mulliken charge of complex 8 and the porphyrin Sc complex TTPScCl[38] with and without coordinated THF. In both cases, the scandium atom is significantly less positively charged in the CTP than in the porphyrin complexes. 

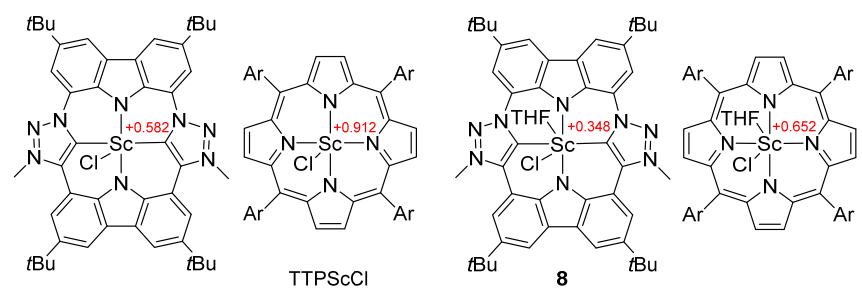

Figure 6. Comparison of the Mulliken population analysis of the scandium metal centres between 8 and TTPScCl $(\mathrm{Ar}=p$-tolyl). The optimized structures (BP86/def2TZVP) are identical within the error of the X-ray structures available.

It is known from the mixed $\mathrm{Cp}$-porphyrin sandwich complex [ScCp(OEP)] (OEP = octaethylprophyrin $)^{[39]}$ that the macrocyclic aromatic ring current exerts a strong shielding effect on the $\mathrm{Cp}-\mathrm{H}$ protons $\left(\delta\left({ }^{1} \mathrm{H}\right) 1.68 \mathrm{ppm}\right)$. To probe a potential ring current in our CTP ligand, we added $\mathrm{CpLi}$ to a solution of complex 8 in tetrahydrofuran- $\mathrm{d}_{8}$. The formation of complex 9 is detected in the ${ }^{45} \mathrm{Sc}$ NMR with a signal at $136.4 \mathrm{ppm}$, which is about $150 \mathrm{ppm}$ at higher field than that of 8 and a good indicator for the substitution by a Cp-ring. ${ }^{[40]} \mathrm{The} \mathrm{Cp}-\mathrm{H}$ signal is detected at $\delta\left({ }^{1} \mathrm{H}\right) 5.21 \mathrm{ppm}\left(\mathrm{LiCp}: \delta\left({ }^{1} \mathrm{H}\right) 5.69 \mathrm{ppm}\right)$, which is comparable to other CpSc complexes. ${ }^{[41]}$ This clearly precludes any macrocyclic aromatic or antiaromatic ring current effect.

To conclude, we have synthesized the carbenaporphyrin ligand 1 (CTP) and complexes thereof. Potential aromatic or antiaromatic properties of an 18 or $20 \pi \mathrm{e}^{-}$macrocycle can be excluded. Instead, the heterocyclic moieties keep their individual aromaticity, but provide the geometric features of porphyrins upon complexation with lithium and scandium. Thus, ligand 1 can be attributed a porphyrinoid character and in addition it features stronger electron donor properties than porphyrins due to the NHC moieties.

\section{Acknowledgements}

T.M. thanks the MWK-BW for a fellowship (Landesgraduiertenförderung). We acknowledge Christina Lutz, Cornelia-Helena Warmutz, Dilan Ehrlich, Ivo Lindenmaier and Ruslan Jaufmann for help with the synthesis as well as Michael Moser, Thomas Hafner and AnnaTheresa Schmidt for their preliminary work. We are also grateful to Fabio Mazzotta and Dr. Wolfgang Leis for the help with NMR measurements.

\section{References}

[1] A. R. Battersby, Nat. Prod. Rep. 2000, 17, 507.

[2] a) B. Meunier, Chem. Rev. 1992, 92, 1411; b) C.-M. Che, J.-S. Huang, Chem. Commun. 2009, 3996; c) T. Chatterjee, V. S. Shetti, R. Sharma, M. Ravikanth, Chem. Rev. 2017, 117, 3254.

[3] S. Liu, D. V. Kondratuk, S. A. L. Rousseaux, G. Gil-Ramírez, M. C. O'Sullivan, J. Cremers, T. D. W. Claridge, H. L. Anderson, Angew. Chem. Int. Ed. Engl. 2015, 54, 5355; Angew. Chem., 2015, 127, 5445-5449.

[4] Y. Ding, W.-H. Zhu, Y. Xie, Chem. Rev. 2017, 117, 2203.

[5] a) G. Calogero, A. Bartolotta, G. Di Marco, A. Di Carlo, F. Bonaccorso, Chem. Soc. Rev. 2015, 44, 3244; b) A. Kay, M. Graetzel, J. Phys. Chem. 1993, 97, 6272.

[6] a) C. M. B. Carvalho, T. J. Brocksom, K. T. de Oliveira, Chem. Soc. Rev. 2013, 42, 3302; b) S. Hiroto, Y. Miyake, H. Shinokubo, Chem. Rev. 2017, 117, 2910.

[7] a) J. Mack, Chem. Rev. 2017, 117, 3444; b) T. Tanaka, A. Osuka, Chem. Rev. 2017, 117, 2584; c) T. Sarma, P. K. Panda, Chem. Rev. 2017, $117,2785$.

[8] T. D. Lash, Synlett 2000, 2000, 279.

[9] a) H. Furuta, T. Asano, T. Ogawa, J. Am. Chem. Soc. 1994, 116, 767; b) P. J. Chmielewski, L. Latos-Grażyński, K. Rachlewicz, T. Głowiak, Angew. Chem. 1994, 106, 805; c) P. J. Chmielewski, L. Latos-Grażyński, K. Rachlewicz, T. Glowiak, Angew. Chem. Int. Ed. Engl. 1994, 33, 779; d) H. Maeda, A. Osuka, H. Furuta, J. Am. Chem. Soc. 2003, 125, 15690.

[10] a) A. Ghosh, Angew. Chem. 1995, 107, 1117; b) A. Ghosh, Angew. Chem. Int. Ed. Engl. 1995, 34, 1028.

[11] a) A. J. Arduengo, R. L. Harlow, M. Kline, J. Am. Chem. Soc. 1991, 113, 361; b) W. A. Herrmann, C. Köcher, Angew. Chem. Int. Ed. Engl. 1997, 36, 2162; c) W. A. Herrmann, C. Köcher, Angew. Chem. 1997, 109, 2256; d) D. Bourissou, O. Guerret, F. P. Gabbaï, G. Bertrand, Chem. Rev. $2000,100,39$.

[12] a) S. Ibáñez, M. Poyatos, E. Peris, Acc. Chem. Res. 2020, 53, 1401; b) E. Peris, Chem. Rev. 2018, 118, 9988; c) N. Sinha, F. E. Hahn, Acc. Chem. Res. 2017, 50, 2167; d) M.-M. Gan, J.-Q. Liu, Le Zhang, Y.-Y. Wang, F. E. Hahn, Y.-F. Han, Chem. Rev. 2018, 118, 9587; e) F. E. Hahn, V. Langenhahn, T. Lügger, T. Pape, D. Le Van, Angew. Chem. 2005, 117, 3825; f) F. E. Hahn, V. Langenhahn, T. Lügger, T. Pape, D. Le Van, Angew. Chem. Int. Ed. 2005, 44, 3759 .

[13] a) S. Richeter, A. Hadj-Aïssa, C. Taffin, A. van der Lee, D. Leclercq, Chem. Commun. 2007, 2148; b) J.-F. Lefebvre, M. Lo, J.-P. Gisselbrecht, O. Coulembier, S. Clément, S. Richeter, Chem. Eur. J. 2013, 19, 15652; c) J.-F. Longevial, A. Langlois, A. Buisson, C. H. Devillers, S. Clément, A. van der Lee, P. D. Harvey, S. Richeter, Organometallics 2016, 35, 663.

[14] M. Toganoh, T. Hihara, H. Furuta, Inorg. Chem. 2010, 49, 8182.

[15] a) J. C. Garrison, W. G. Kofron, R. S. Simons, C. A. Tessier, W. J. Youngs, US2004097723A1, 2001; b) R. S. Simons, J. C. Garrison, W. G. Kofron, C. A. Tessier, W. J. Youngs, Tetrahedron Lett. 2002, 43, 3423.

[16] M. Moser, Ph.D. thesis, Ruprecht-Karl-Universität Heidelberg, Heidelberg, 2007.

[17] K. Lin, L.-E. Chile, S. C. Zhen, P. D.W. Boyd, D. C. Ware, P. J. Brothers, Inorg. Chim. Acta 2014, $422,95$.

[18] M. Moser, B. Wucher, D. Kunz, F. Rominger, Organometallics 2007, 26, 1024.

[19] T. Hafner, PhD thesis, Ruprecht-Karl-Universität Heidelberg, Heidelberg, 2009 
[20] J. Bouffard, B. K. Keitz, R. Tonner, V. Lavallo, G. Guisado-Barrios, G. Frenking, R. H. Grubbs, G. Bertrand, Organometallics $2011,30,2617$.

[21] G. Guisado-Barrios, J. Bouffard, B. Donnadieu, G. Bertrand, Angew. Chem. Int. Ed. 2010, 49, 4759.

[22] D. I. Bezuidenhout, G. Kleinhans, G. Guisado-Barrios, D. C. Liles, G. Ung, G. Bertrand, Chem. Commun. 2014, 50, 2431.

[23] a) A.-T. Schmidt, Diploma thesis, Eberhard Karls Universität Tübingen, Tübingen, 2013; b) A.-T. Schmidt, Ph.D. thesis, Eberhard Karls Universität Tübingen, Tübingen, 2018.

[24] a) Q. Wang, T. R. Chan, R. Hilgraf, V. V. Fokin, K. B. Sharpless, M. G. Finn, J. Am. Chem. Soc. 2003, 125, 3192; b) C. W. Tornøe, C. Christensen, M. Meldal, J. Org. Chem. 2002, 67, 3057; c) M. Meldal, C. W. Tornøe, Chem. Rev. 2008, 108, 2952

[25] a) H. C. Kolb, M. G. Finn, K. B. Sharpless, Angew. Chem. Int. Ed. Engl. 2001, 40, 2004; b) H. C. Kolb, M. G. Finn, K. B. Sharpless, Angew. Chem. 2001 113, 2056.

[26] H.-C. Gee, C.-H. Lee, Y.-H. Jeong, W.-D. Jang, Chem. Commun. 2011, 47, 11963.

[27] I. Pryjomska-Ray, D. Zornik, M. Pätzel, K. B. Krause, L. Grubert, B. Braun-Cula, S. Hecht, C. Limberg, Chem. Eur. J. $2018,24,5341$.

[28] D. Zornik, R. M. Meudtner, T. El Malah, C. M. Thiele, S. Hecht, Chem. Eur. J. 2011, 17, 1473

[29] L. Arnold, PhD thesis, Johannes Gutenberg-Universität Mainz, Mainz, 2012

[30] B. K. Reddy, A. Basavarajappa, M. D. Ambhore, V. G. Anand, Chem. Rev. 2017, 117, 3420.

[31] a) C. Maeda, T. Yoneda, N. Aratani, M.-C. Yoon, J. M. Lim, D. Kim, N. Yoshioka, A. Osuka, Angew. Chem. 2011, 123, 5809; b) C. Maeda, T. Yoneda, N. Aratani, M.-C. Yoon, J. M. Lim, D. Kim, N. Yoshioka, A. Osuka, Angew. Chem. Int. Ed. Engl. 2011, 50, 5691; c) L. Arnold, M. Baumgarten, K. Müllen, Chem. Commun. 2012, 48, 9640; d) L. Arnold, H. Norouzi-Arasi, M. Wagner, V. Enkelmann, K. Müllen, Chem. Commun. 2011, 47, 970.

[32] G. Calogero, G. Di Marco, S. Caramori, S. Cazzanti, R. Argazzi, C. A. Bignozzi, Energy Environ. Sci. 2009, 2, 1162.

[33] a) D. Tapu, D. A. Dixon, C. Roe, Chem. Rev. 2009, 109, 3385; b) V. Nesterov, D. Reiter, P. Bag, P. Frisch, R. Holzner, A. Porzelt, S. Inoue, Chem. Rev. 2018, 118, 9678

[34] K. S. Flaig, B. Raible, V. Mormul, N. Denninger, C. Maichle-Mössmer, D. Kunz, Organometallics 2018, $37,1291$.

[35] D. Y. Dawson, J. Arnold, J. Porphyrins Phthalocyanines 1997, 1, 121.

[36] C. R. Groom, I. J. Bruno, M. P. Lightfoot, S. C. Ward, Acta Crystallogr., Sect. B: Struct. Sci 2016, 72, 171

[37] A. S. de Sousa, M. A. Fernandes, W. Nxumalo, J. L. Balderson, T. Jeftič, I. Cukrowski, H. M. Marques, J. Mol. Struct. 2008, 872, 47.

[38] M. G. Sewchok, R. C. Haushalter, J. S. Merola, Inorg. Chim. Acta 1988, 144, 47.

[39] a) J. Arnold, C. G. Hoffman, J. Am. Chem. Soc. 1990, 112, 8620; b) J. Arnold, C. G. Hoffman, D. Y. Dawson, F. J. Hollander, Organometallics 1993, 12, 3645 .

[40] D. Barisic, D. Diether, C. Maichle-Mössmer, R. Anwander, J. Am. Chem. Soc. 2019, 141, 13931.

[41] a) P. Bougeard, M. Mancini, B. G. Sayer, M. J. McGlinchey, Inorg. Chem. 1985, 24, 93; b) M. Mancini, P. Bougeard, R. C. Burns, M. Mlekuz, B. G. Sayer, J. I. A. Thompson, M. J. McGlinchey, Inorg. Chem. 1984, 23, 1072. 